\title{
ANÁLISE DIATÓPICO-DIACRÔNICA DOS COMPLEMENTOS PRONOMINAIS DE VERBOS NA ESCRITA BRASILEIRA DOS SÉCULOS XIX E XX
}

\section{DIATOPIC-DIACHRONIC ANALYSIS OF VERBS PRONOUN COMPLEMENTS IN BRAZILIAN WRITING OF THE $19^{\mathrm{TH}}$ AND $20^{\mathrm{TH}}$ CENTURIES}

\author{
Marco Antonio Rocha Martins | Lattes | marco.martins@ufsc.br \\ Universidade Federal de Santa Catarina | CAPES-Instituto Humboldt | CNPq
}

Kássia Kamilla de Moura | Lattes | moura.kassia@gmail.com Universidade Federal do Rio Grande do Norte

Franklin Costa da Silva | Lattes | nilknarf28@hotmail.com Universidade Federal do Rio Grande do Norte

Resumo: No campo disciplinar da sintaxe diacrônica, apresentamos neste artigo um mapeamento diatópico-diacrônico dos pronomes complementos de verbos com referência à segunda pessoa, com foco nas formas dativas, em cartas pessoais escritas no Brasil dos séculos XIX e XX. Esse mapeamento nos permite sistematizar argumentos a favor da hipótese de que formas inovadoras da gramática do $\mathrm{PB}$ se implementam primeiro na região Nordeste quando comparada com as regiões Sudeste e Sul no vasto território brasileiro. Os resultados mostram para a região Nordeste um quadro em que formas associadas ao pronome você são mais recorrentes para os complementos verbais nas funções acusativa, dativa e oblíqua, de um modo geral, e que as formas dativas, de modo mais particular, (1) o pronome te é significativamente pouco frequente e o pronome lhe se mostra implementado no sistema pronominal desde o início do século XX e (2) a frequência de nulos e de formas preposicionadas (preposição + você/tu) aumenta significativa e gradativamente no curso do século XX. Esse quadro se contrasta àquele encontrado para as regiões Sudeste e Sul, sobretudo no marco temporal em que tais mudanças se implementam na escrita.

Palavras-chaves: Dativos; Formas pronominais completivas; Cartas particulares; Português Brasileiro; Mudança diatópica. 
Abstract: In the field of diachronic syntax, we present in this article a diatopic-diachronic mapping of second person verbal complements, focusing on the dative forms, in personal letters written in Brazilian Northeast in both $19^{\text {th }}$ and $20^{\text {th }}$ centuries. This mapping allows us to systematize arguments in favor of the hypothesis that innovative forms of BP grammar are first implemented in the Northeast when compared to the Southeast and South in the vast Brazilian territory. Results demonstrate that, in the Northeast, forms associated with the pronoun você are more recurrent for verbal complements in the accusative, dative and oblique functions, in general, and that, for the dative forms, in particular, (1) te is significantly infrequent while the has been implemented in the pronominal system since the beginning of the 20th century; and (2) the frequency of null and of prepositional forms (preposition + "você/tu") has significantly and gradually increased during the $20^{\text {th }}$ century. These results contrast with those found for the Southeast and South of Brazil, especially in the time frame in which these changes are implemented.

Keywords: Datives; Personal pronouns; Private letters; Diachronic syntax; Brazilian Portuguese; Diatopic change.

\section{Introdução ${ }^{1}$}

Apresentamos neste artigo uma análise diatópico-diacrônica das formas pronominais completivas de verbo com referência à segunda pessoa, com foco nos complementos dativos, em cartas pessoais escritas no Brasil no curso dos séculos XIX e XX. O objetivo é sistematizar argumentos para a hipótese defendida em Martins et al. (2015) e Martins (a sair) de que a escrita da região Nordeste do Brasil apresenta características mais inovadoras já em finais do século XIX e início do XX quando comparada a outras regiões no vasto território brasileiro. Para cumprir esse objetivo, retomamos resultados dos estudos de Moura (2017) sobre os complementos verbais nas funções acusativa, dativa e oblíqua e de Costa da Silva (2017) sobre as formas dativas e apresentamos um mapeamento das mudanças nas formas de complemento com referência à segunda pessoa em cartas pessoais escritas no Nordeste brasileiro. Destacamos que são mobilizados na análise pres-

\footnotetext{
${ }^{1}$ Marco Antonio Rocha Martins destaca que este artigo foi escrito durante o período em que foi Visiting Professor na Universidade de Colônia/Alemanha: Projeto "Position of the subject and proclisis in neutral contexts $[\mathrm{XP}] \mathrm{V}$ in 19th century Brazilian writing: Reflexes of a parametric change in BP", financiado por uma bolsa de estudos do Instituto Humboldt/CAPES (Processo número 88881.145464/2017-01). Este projeto está integrado ao projeto "A posição do sujeito pré-verbal e das estruturas [XP-clitic-Verb] na escrita brasileira do século XIX”, financiado pelo CNPq com a bolsa de estudos de produtividade PQ-2 (processo 310094/2017-8). Agradecemos aos pareceristas da Revista pelas valiosas leituras e contribuições. Os erros remanescentes são de nossa inteira responsabilidade.
} 
supostos da sociolinguística variacionista (cf. WEINREICH; LABOV; HERZOG, 2006 [1968]) e da sociolinguística histórica (cf. CONDE SILVESTRE, 2007), assim como do modelo de Brown e Gilman (1960).

Uma análise dessa natureza se justifica porque apesar de haver muitos estudos sobre formas pronominais em outras funções gramaticais poucos são os que verticalizam a discussão para as formas completivas, e, mais especificamente, as dativas.

O corpus analisado se constitui de 410 cartas pessoais escritas nos séculos XIX e XX em três estados da região Nordeste: 296 cartas do Rio Grande do Norte, 36 cartas de Pernambuco, e 78 cartas da Bahia. Parte dessas cartas pertence ao banco de dados do Projeto História do Português Brasileiro (PHPB), que, em âmbito nacional e organizado em equipes regionais, busca coletar, editar e catalogar materiais referentes a gêneros textuais diversos, com o objetivo de contribuir para o estudo da história do português escrito no Brasil ${ }^{2}$. Mais informações sobre o corpus serão apresentadas nas seções 2 e 3 .

As categorias morfossintáticas de complementos verbais analisadas neste artigo vão além das formas tratamentais tu e você propriamente ditas; antes, se estendem àquelas associadas ao pronome tu ou a um sistema de tuteamento e ao pronome você ou a um sistema de voceamento, além, é claro, das formas nulas associadas a um ou a outro sistema. Em relação às categorias morfossintáticas de complementos verbais acusativos, as variantes encontradas na diacronia do português escrito no Brasil, no curso dos séculos, são os pronomes te $(1)^{3}, o / a(2)$, lhe (3), você (4) e formas nulas $\varnothing(5)$ :

(1) [...] Deixe-me andar assim no teu caminho, por toda a vida amor, de vagarinho até a morte me levar consigo... tu és a vida da minha própria vida por isso e que TE amo amo $365 \mathrm{X} 365$, que Deus TE conserve bonita e bela para $\operatorname{mim}[\ldots . .$. . (Carta de Walter Oliveira para Lucinha, 31|03|93).

(2) [...] V. já deve saber que não O esqueci. É que estava doente. [...]. (Carta de Câmara Cascudo para Mário de Andrade, 17/4/1925).

(3) [...] Aqui estar tudo bem comigo graças a Deus, e desejo que esta chegue em suas maos e LHE encontre com muita saude e que você alcance todos os seus objetivos[...]. (Carta de Walter Oliveira para Lucinha, 18|10|92).

(4) [...] Minhas lembranças a todos os seus. Mamãi e papai, Cotinha e minha

\footnotetext{
${ }^{2}$ As cartas utilizadas por Costa da Silva (2017) estão disponíveis no site do Projeto PHPB, acessível em: https://sites.google.com/site/corporaphpb/home/corpora-manuscritos. Das cartas utilizadas por Moura (2017), parte está disponível no site do projeto e parte são documentos inéditos organizados pela autora.

${ }^{3}$ Os dados citados neste artigo foram extraídos, em sua maioria, de Moura (2017) e Costa da Silva (2017). Trazem informações sobre os escreventes, o local e a data de escrita das cartas.
} 
mulher, todos abraçam V. desejando felicidades e a prompta sahida de João Alberto[...]. (Carta de Câmara Cascudo para Mário de Andrade, 27/4/31).

(5) [...]Meu amor, lamento sinceramente que tenhas dúvidas sobre este que tanto te ama e que $\varnothing$ admira sobre este que é capaz de dar a vida por ti caso fosse preciso. Te adoro. Lucinha vai estes pensamentos especialmente pra você. [...] (Carta de Walter Oliveira para Lucinha, 8|12|92).

as variantes para as formas dativas são: te e prep. $+t i(6)$, the (7), prep. + você/tu (8), e formas nulas $\varnothing(9)$ :

(6) venho mesmo com a pobreza de minha inteligencia diser-TE que Hoje destante de TI. (Ruzinete a Lourival, Patu, 26 de-2-1946).

(7) LHE mandei por José Carambola, que ja LHE forneci as listas (João a Thodosio de Paiva, Monte Alegre, 6-06-1917).

(8) a. agradeço tudo isto A VOCÊ. (Walter a Lucinha, Diadema, 21-07-1994).

b. Lucinha liguei PRÁ VOCE no dia de seu aniversario. (Walter a Lucinha, sem local e data).

b. PARA VOCÊ milhoes de beijos. (Walter a Lucinha, sem local e data).

b. [...] Mas não perdi a esperança, os dias correm até que o tempo chega, pois, o passado nêgro não quero ja mais, apelo PARA TU, para o futuro para que o meu sonho sêja realizado[...]. (Carta de Lourival para Ruzinete, 17/2/1946).

(9) Não mandei hotem as gallinhas $\varnothing$ (João a Theodosio de Paiva, Monte Alegre 8-05-1917) e para remeter o dito algodão Ø. (João a Theodosio de Paiva, Monte Alegre, 4-10-1918).

as variantes para as formas oblíquas são: prep. + você $(10)$ e formas nulas $\varnothing(11)$ :

(10) a. [...] você é uma pessoa muito marcante que marcou minha vida para sempre, quando estou COM VOCÊ do meu lado esqueço que o mundo existi para me será amor ou paixão acho que é mais que amor é algo bem diferente [...]. (Carta de Walter Oliveira para Lucinha, $5|5| 92$ ).

b. Tudo isso é feito sem que me esqueça DE VOCÊ. Do quanto você é capaz de fazer, alem do ótimo que fez e faz. Aprenda a escrever carta comprida, seu bilheteiro. (Carta de Câmara Cascudo para Mário de Andrade, 19|10|41). 
(11) [...] O melhor que tenho tido em minha vida é não esperar senão bonde e missa. Idéas, elogios, rapapés, frechisbeques litterários, vem quando contra o provável. Tradução - a única maneira d'eu desconfiar $\varnothing$ e de seu talento seria um livro compreendido inteiramente. [...]. (Carta de Câmara Cascudo para Mário de Andrade, 25|8|24).

O artigo está organizado em quatro seções, além desta introdução e das referências. Em 1, apresentamos um breve panorama da implementação do pronome você na função de sujeito no português escrito no Brasil dos séculos XIX e XX, considerando especificamente as regiões Nordeste, Sudeste e Sul do país; em 2, apresentamos resultados sobre os complementos acusativos, dativos e oblíquos com referência à segunda pessoa do singular em cartas pessoais do Rio Grande do Norte; em 3, apresentamos resultados sobre o complemento dativo com referência à segunda pessoa do singular e plural em cartas pessoais de três estados da região Nordeste; e em 4, para concluir, sumarizamos os resultados empíricos encontrados em busca de evidências para a hipótese aqui investigada.

\section{A implementação do pronome você na função de sujeito no português do Brasil}

Apresentamos aqui, muito brevemente, um quadro panorâmico da implementação do pronome você em oposição ao pronome tu na posição de sujeito no português escrito no Brasil dos séculos XIX e XX, considerando diferentes estudos com base em cartas pessoais escritas nas regiões Nordeste (1.1), Sudeste (1.2) e Sul (1.3) do país.

\subsection{Região Nordeste}

Martins et al. (2015) analisaram 813 cartas pessoais escritas por brasileiros nascidos nos estados do Rio Grande do Norte (RN), de Pernambuco (PE) e da Bahia (BA) ${ }^{4}$. A análise contemplou as motivações sócio-pragmáticas e as relações interpessoais entre os escreventes condicionadoras para o uso de formas tratamentais. Os resultados gerais mostraram que o pronome você em oposição ao pronome $t u$, como forma de tratamento nos mesmos contextos sócio-discursivos, mesmo em relações simétricas, estava já implementado em cartas pessoais da primeira década do século XX, ou mesmo antes, no

\footnotetext{
${ }^{4} \mathrm{Na}$ amostra da Bahia (BA), foram analisadas 383 cartas pessoais, relativas ao período de 1810 a 1990 , do acervo do Corpus Eletrônico de Documentos Históricos do Sertão (CE-DOHS) e identificados 838 dados de formas de tratamento de referência à segunda pessoa na posição de sujeito, entre sujeitos preenchidos e nulos (Vossa Excelência, Vossa senhoria, o senhor, Vossa mercê e tu); na amostra de Pernambuco (PE), foram analisadas 126 cartas pessoais datadas de 1869 a 1969 e identificados 354 dados de formas tratamentais (você, tu, Vossa Mercê e o/a senhor/a); na amostra do Rio Grande do Norte (RN), foram analisadas 304 cartas e levantados 892 dados de formas tratamentais (você, tu e o/a senhor/a). As cartas de PE e do RN estão em sua maioria disponíveis no site dos corpora do Projeto para a História do Português Brasileiro. A análise dos autores é retomada em Lopes et al. (2018).
} 
final do século XIX. Dos diferentes subsistemas de tratamento na escrita brasileira dos séculos XIX e XX - (i) de você exclusivo, (ii) de tu exclusivo e (iii) de alternância você $\sim$ tu - propostos por Lopes e Cavalcante (2011), Martins et al. (2015) apresentam evidências empíricas robustas de que, em cartas da região Nordeste, o subsistema de tratamento que vigorou desde o final do século XIX foi o de você exclusivo na posição de sujeito, conforme exemplifica o excerto em (12) a seguir e ilustram os gráficos da Figura 1, a seguir.

(12) [... Eu queria que VOCÊ fosse lá na $4^{\text {a }}$ feira (amanhã é feriado) e CONVERSASSE em meu nome com o chefe da casa a respeito do assumpto. Caso elles possam enviar o radio, VOCÊ peça para no trem de $5^{\text {a }}$ feira pois eu tenho desejo de revever [inint.] com ingenho, depois de experimentar outros apparelhos - Outro pedio: VOCÊ procure tambem o Edvaldo Guimarães (o do seu Joaquim) e indique aelle dos rádios Philco que possuo, bons, e de preço equivalente ao 141 Victor, K. 80 G.E. etc. si puder, PEÇA para avaliar. [...] (de Mário Sette para o filho, 29 de outubro de 1937, Pernambuco/Acervo Mário Sette).

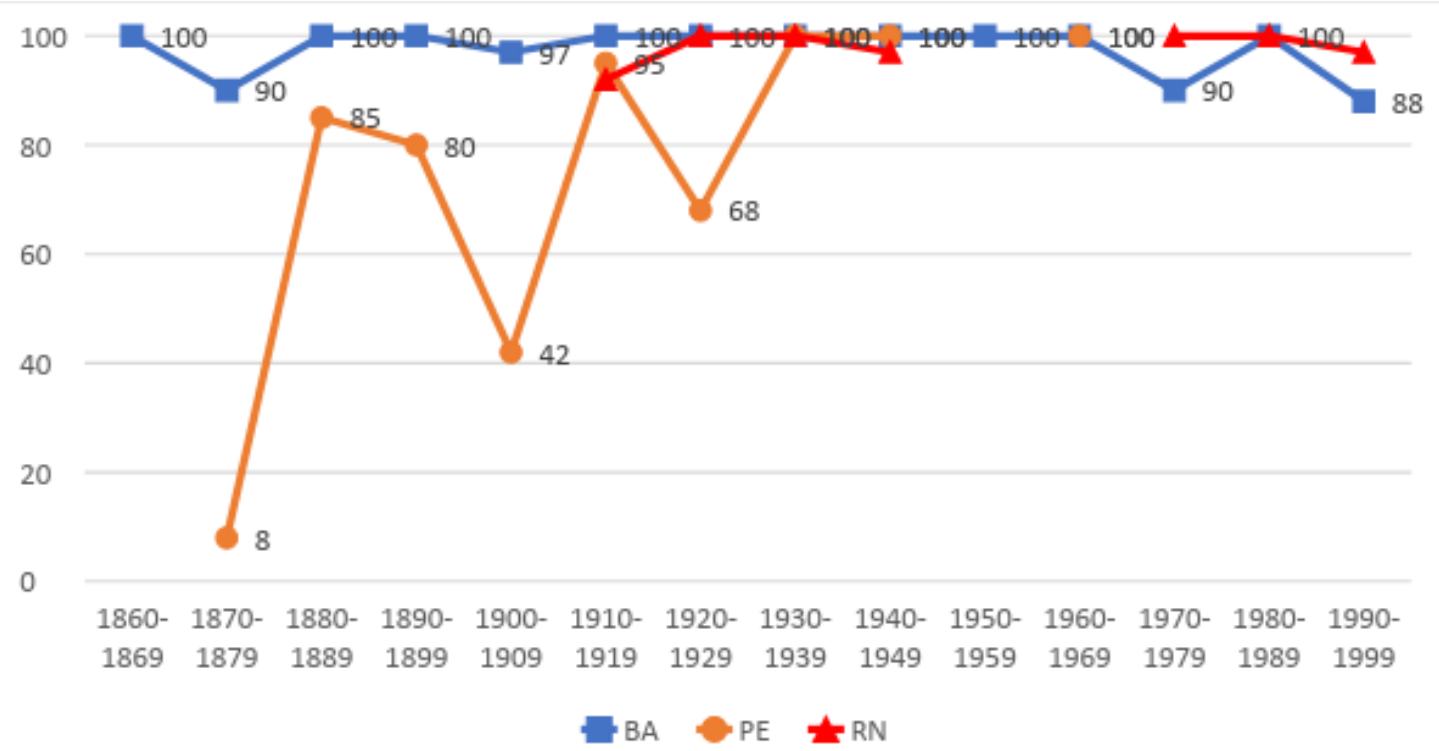

Figura 1: Implementação do pronome você na posição de sujeito em cartas pessoais da região Nordeste: Rio Grande do Norte, Pernambuco e Bahia (1860-1999), resultados adaptados de Martins et al. (2015, p. 46) .

\footnotetext{
${ }^{5}$ Os resultados apresentados nos gráficos fazem referência ao total de uso das formas você versus tu nos resultados encontrados. Para observar aqui a implementação de você nos mesmos contextos sóciodiscursivos de $t u$, foram excluídos os usos das demais formas tratamentais nas cartas (Vossa Excelência, Vossa senhoria, o senhor e Vossa mercê). Para uma análise pormenorizada, remetemos o leitor a Martins et al. (2015).
} 
Em cartas baianas, o pronome você aparece já como uma forma consolidada no sistema de tratamento da segunda metade do século XIX (entre 1860 e 1899), com percentuais de/ou muito próximos a 100\%, em oposição ao pronome $t u^{6}$.

Em cartas pernambucanas, de igual modo, há um "forte predomínio" do uso do pronome você em finais do século XIX: 80\% em 1980-1889, na média dos 80\% em cartas das últimas décadas desse século, com a consolidação desse uso em cartas do século XX (100\% nas últimas décadas analisadas). Os 64 usos do pronome $t u$ da amostra (do total de 354 dados analisados com todos os pronomes), distribuídos ao longo do período analisado, estão sempre associados a motivações sócio-pragmáticas, ocorrendo eventualmente nas relações assimétricas descendentes (entre pais e filhos) e em relações simétricas em contextos mais íntimos entre amigos e entre casais, com temáticas amorosas.

Em cartas norte-rio-grandenses, o você é a forma pronominal categórica já em cartas da primeira década do século XX (92\%) e os usos do pronome tu são motivados por relações amorosas e fraternais - cartas de namorado(a)/noivo(a) para namorada/noiva; e de marido para mulher ou e de mulher para marido ${ }^{7}$.

Esse quadro mostra que a frequência do pronome você na região Nordeste sempre foi mais alta em comparação com a variante tu, desde os finais do século XIX. Prevalece, portanto, um subsistema de tratamento de você (quase) exclusivo, já bastante consolidado como forma tratamental.

\subsection{Região Sudeste}

Como muitos trabalhos têm evidenciado, o quadro apresentado na subseção anterior não é aquele encontrado nas regiões Sudeste e Sul do Brasil. Lopes et al. (2018), retomando estudos anteriores (LOPES; RUMEU, 2015; entre outros), apresentam uma excelente descrição das formas tratamentais na região Sudeste, no estados do Rio de Janeiro, São Paulo e Minas Gerais e sistematizam uma análise de 522 cartas pessoais dos

\footnotetext{
${ }^{6}$ Quando consideradas todas as formas tratamentais encontradas, os autores mostram uma baixa frequência do pronome você no final do século XIX (14,3\%) em oposição às demais formas de tratamento (Vossa Excelência, Vossa senhoria, o senhor, Vossa mercê e tu), mas a frequência de uso desse pronome sobe para $100 \%$ logo no início do século XX, entre 1900 e 1929, como mostra o gráfico na Figura 1. Uma segunda forma muito recorrente nas cartas do século XIX foi o pronome Vossa Excelência. Citando Martins et al. (2015, p. 30): "Vossa Excelência aparece nas cartas com $40 \%$ de frequência na primeira metade do século XIX (1810-59), atingindo $82 \%$ na segunda metade daquele século”.

${ }^{7} \mathrm{Na}$ amostra do Rio Grande do Norte, há cartas do período de 1940 a 1959 com altos índices de tu (62\% e $100 \%)$, mas são todos dados em cartas de amor trocadas entre o casal Lourival e Ruzinete. Por entendermos aqui que são usos motivados por relações interpessoais e por contexto amoroso das cartas, esses dados foram excluídos do gráfico na Figura 1. Para mais detalhes a respeito ver Moura (2013), Martins et al. (2015) e Lopes et al. (2018).
} 
séculos XIX e $\mathrm{XX}^{8}$. A implementação do pronome você em cartas pessoais nesses estados pode ser observada nos gráficos da figura 2 a seguir:

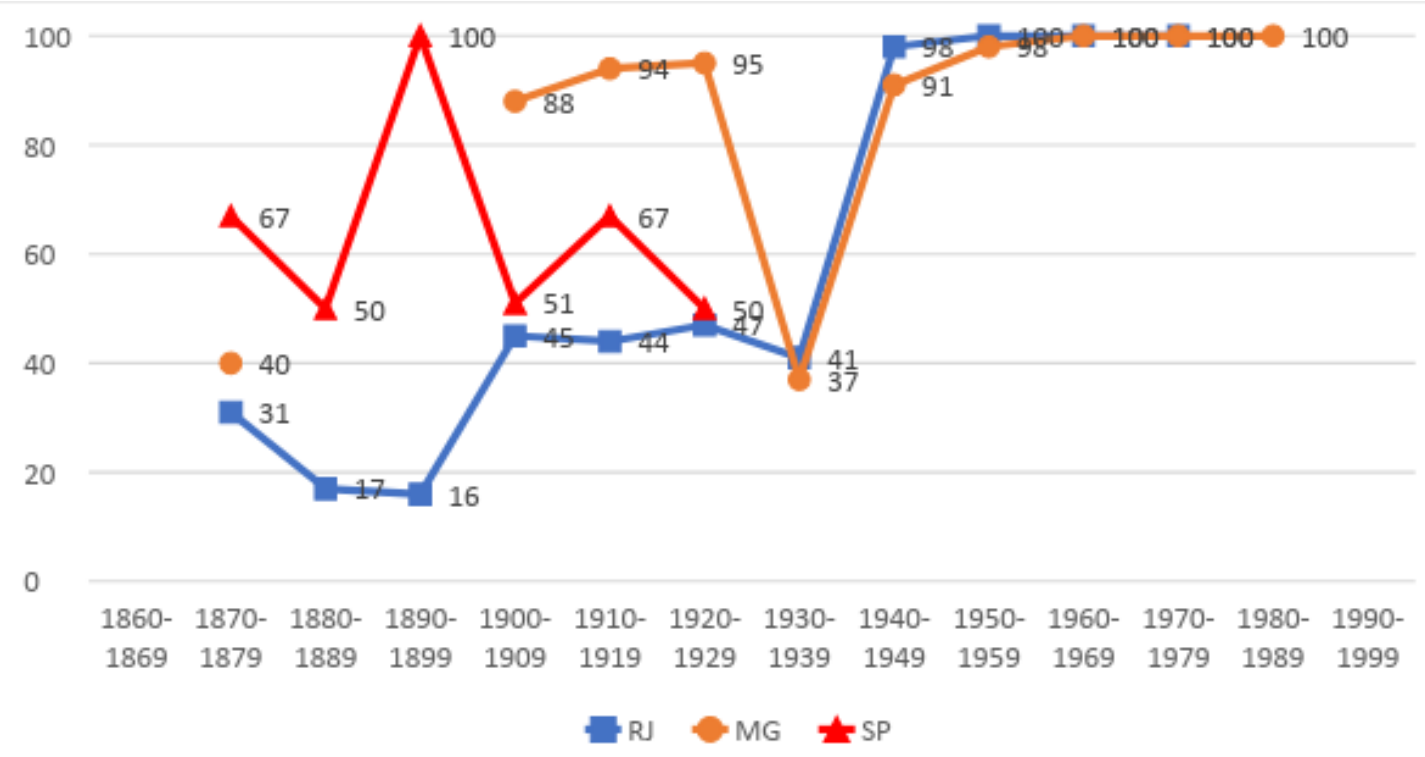

Figura 2: Implementação do pronome você na posição de sujeito em cartas pessoais da região Sudeste: Rio de Janeiro, São Paulo e Minas Gerais (1860-1999), resultados adaptados de Lopes et al. (2018, p. 50, 69 e 82)

Em cartas cariocas, o pronome você não foi produtivo até o início do século $\mathrm{XX}$ (com percentuais de 31\% em 1870-1879, 17\% em 1880-1889 e 16\% em 1890-1899) quando comparado ao uso do pronome tu. A partir da década de 1930, há um significativo aumento no uso de você, de 41\% em cartas de 1930-1939 para uma média de 98\% em 1940-1949 e atinge 100\% nos demais períodos da segunda metade do século XX. A curva desenhada pelo gráfico leva Lopes et al. (2018) à hipótese de que houve três estágios na implementação de você, tendo em vista a análise de cartas escritas no RJ: "I. de 1870 a 1899: tu era mais frequente que você; II. de 1900 a 1939: tu e você apresentando frequências próximas; III. de 1940 a 1979: predomínio de você sobre tu." (LOPES et al., 2018, p. 50).

Em cartas mineiras, considerando a totalidade dos dados, há uma "alta produtividade de você, $84 \%$ (189 dados), em oposição às baixíssimas frequências de uso de tu,

\footnotetext{
${ }^{8} \mathrm{Na}$ amostra do Rio de Janeiro (RJ), foram analisadas 366 cartas pessoais escritas entre 1870 e 1979 e identificados 1.525 dados de você e $t u$; na mostra de Minas Gerais (MG), foram observadas 89 cartas mineiras escritas entre 1850 e 1989 e 266 dados de você, tu e Vossa Mercê; na amostra de São Paulo (SP), foram analisadas 67 cartas escritas entre 1870 e 1930 e identificados 148 dados de você, tu, o/a senhor/a, Vossa Senhoria e Vossa Excelência em posição de sujeito.
} 
12\% (28 dados) e do Vossa Mercê, 4\% (9 dados)” (Lopes et al., 2018, p. 50). Há, ainda, uma concentração do uso do pronome tu em cartas da década de 1930, que, nas palavras desses autores, é motivada por "relações familiares de superior para inferior das cartas mineiras novecentistas: de pais para filhos e entre irmãs." (p. 76). De um modo geral, portanto, o sistema com você exclusivo parece ter sido o que vigorou nas cartas mineiras desde a primeira década do século XX, com uma média de $90 \%$, e a queda dessa forma na década de 1930 a 1939 seria motivada pela natureza da amostra, nas palavras dos autores.

Esse mesmo quadro pode ser encontrado em cartas paulistas de 1870 a 1930, em que a análise "aponta para a tendência de que o pronome você apresenta um uso majoritário ao longo do tempo, compreendido como uma estratégia neutra que perpassa a maioria das relações sociais." (LOPES et al., 2018, p. 90). No equilíbrio entre o uso dos pronomes você e $t u$, dos dados analisados para SP, a variante tu desinencial "ocorre em contextos em que há a intenção de estabelecer intimidade e afeto" (p. 90).

Em MG e em SP, portanto, o quadro se diferencia, em parte, daquele encontrado para o RJ, em que a frequência de uso do pronome você aumenta significativamente na década de 1930.

\subsection{Região Sul}

Um quadro ainda mais diferente em relação à implementação do pronome você na função de sujeito tem sido desenhado em trabalhos com dados de Santa Catarina, na região Sul do Brasil. Nunes de Souza e Coelho (2013; 2015), com base na análise de 71 cartas pessoais escritas por ilustres e não ilustres de duas cidades - Florianópolis e Lages -, mostram que o pronome você parece estar ainda em processo de implementação durante o século XX. Há, de acordo com as autoras, diferenças diatópicas relevantes entre as cidades de Florianópolis (no litoral) e Lages (na serra), de modo que ainda na segunda metade do século XX há altos índices de tu na função de sujeito9.

Da implementação do pronome você na função de sujeito no português escrito no Brasil, portanto, podemos concluir que parece haver diferenças diacrônica-diatópicas entre três regiões do Brasil: você parece se implementar como pronome sujeito em cartas da região Nordeste ainda em finais do século XIX, e esse mesmo quadro parece ser o encontrado em cartas de MG e SP, desconsideradas as poucas ocorrências de tu. Diferentemente, em cartas do RJ, há uma clara implementação do você na escrita a partir da década de 1930. Em cartas de SC, a implementação parece ainda estar em processo no curso da segunda metade do século XX.

\footnotetext{
9 Esses resultados são retomados em Lopes et al. (2018).
} 


\section{Formas pronominais completivas de verbo com referência à segunda pessoa do} singular em cartas pessoais no Rio Grande do Norte/região Nordeste

Moura (2017) analisou as formas de complementos verbais com referência à segunda pessoa do singular, nas funções acusativa, dativa e oblíqua, em 296 cartas pessoais escritas no estado do Rio Grande do Norte, no Nordeste brasileiro, no período de 1916 a 1994, como ilustram as informações sistematizadas no quadro 1 a seguir ${ }^{10}$ :

\begin{tabular}{|c|c|c|c|}
\hline $\begin{array}{c}\text { CONJUNTOS DE CARTAS, } \\
\text { ORGANIZADOS POR INFORMANTES }\end{array}$ & $\begin{array}{c}\text { PERÍODO DE } \\
\text { ESCRITA }\end{array}$ & $\begin{array}{c}\text { NÚMERO DE } \\
\text { CARTAS }\end{array}$ & $\begin{array}{c}\text { SUBSISTEMA } \\
\text { UTILIZADO NA } \\
\text { POSIÇÃo DE SUJEITO }\end{array}$ \\
\hline Irmãos Paiva & $1916-1925$ & 61 & Exclusivo de você \\
\hline Câmara Cascudo - ilustre & $1924-1944$ & 84 & Exclusivo de você \\
\hline José Geraldo & $1943-1944$ & 32 & $\begin{array}{c}\text { Exclusivo de } \\
\text { senhor }(a)\end{array}$ \\
\hline Lourival Rocha & $1946-1972$ & 34 & Misto $($ tu você $)$ \\
\hline Rusinete Dantas & $1946-1951$ & 16 & Exclusivo de $t u$ \\
\hline Joana Rocha & $1973-1989$ & 20 & Exclusivo de você \\
\hline Desemb. Manoel Onofre - ilustre & $1973-1999$ & 19 & Exclusivo de você \\
\hline Walter Oliveira & $1992-1994$ & 30 & Misto $($ tu você $)$ \\
\hline
\end{tabular}

Tabela 1: Corpus de cartas pessoais analisado por Moura (2017).

A autora fez uma análise variacionista dos complementos verbais, de acordo com os pressupostos da Sociolinguística histórica (CONDE SILVESTRE, 2007), considerando (1) formas de tu versus formas de você, para a totalidade dos dados e para cada uma das três funções em separado, e (2) formas preenchidas versus nulos, para a totalidade dos dados e para cada uma das três funções em separado. Foram encontradas 646 ocorrências entre formas preenchidas (que somam 591) e nulas (que somam 55); do total de formas pronominais preenchidas, foram analisadas $218(36,9 \%)$ associadas ao pronome tu e 373 $(63,7 \%)$ associadas ao você, o que mostra uma preferência pelas formas associadas ao pronome inovador também na posição de complemento verbal nessas cartas, do estado do Rio Grande do Norte, no Nordeste brasileiro. No que concerne às funções sintáticas das formas pronominais de $\mathrm{P} 2$, do total de 591 dados, a distribuição dos dados é a seguinte: 305 (51,6\%) ocorrências de formas pronominais de P2 na função dativa; 220 (37,3 \%)

\footnotetext{
${ }^{10}$ Seguindo a proposta de Lopes e Cavalcante (2011), o corpus foi organizado de acordo o subsistema pronominal na posição de sujeito encontrado nas cartas, de tu, você ou o senhor exclusivo, ou de misto. $\mathrm{O}$ corpus se organiza em escreventes "ilustres" para designar pessoas que tiveram, além do acesso ao ensino superior, uma vida pública reconhecida versus “não ilustres”. Mais informações sobre o corpus, remetemos ao trabalho de Moura (2017).
} 
dados de formas pronominais de P2, na função acusativa e 66 (11,2\%) ocorrências de formas pronominais de $\mathrm{P} 2$, na função oblíqua.

A distribuição das formas pronominais associadas aos pronomes tu e você nas cartas por escrevente no curso do século XX pode ser visualizada Figura 3 a seguir:

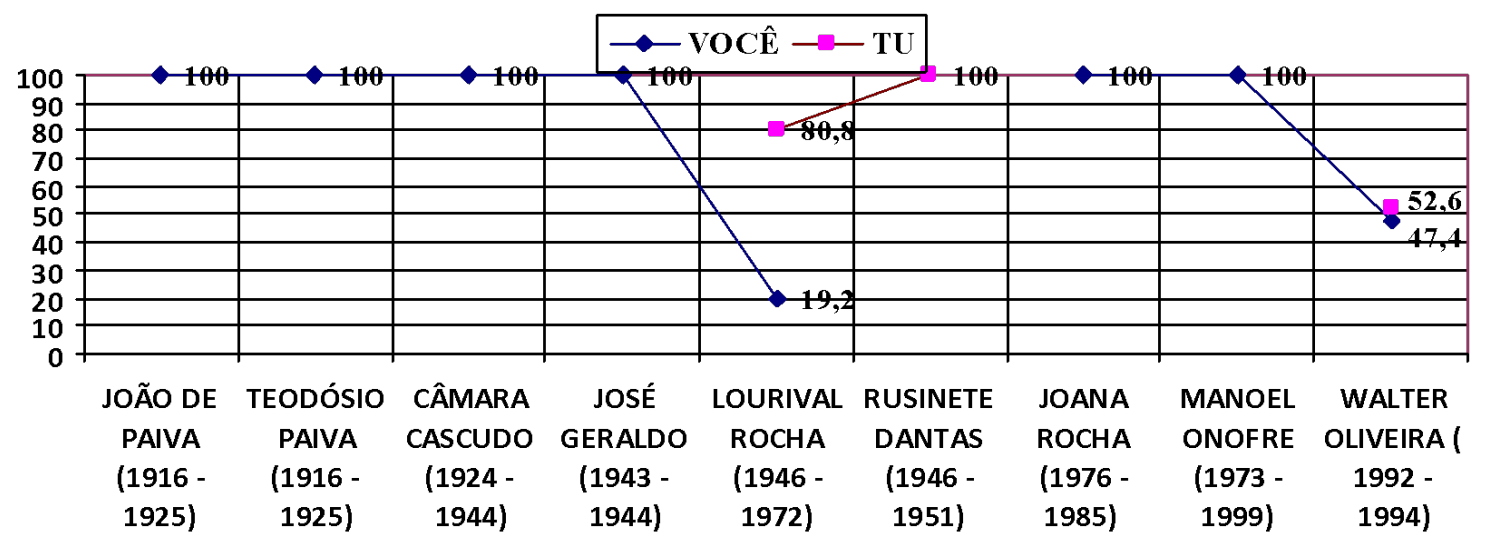

Figura 3: Complementos verbais com referência à segunda pessoa do singular em cartas do RN em função do escrevente (MOURA, 2017, p. 105).

Em quase todas as décadas do século $\mathrm{XX}$, as formas pronominais de $\mathrm{P} 2$ na posição de complemento estão associadas (categoricamente, 100\%) ao pronome você, o que confirma nossa hipótese de que o pronome você parece ser o padrão na escrita da região Nordeste no curso de todo o século XX, também nessa função. Somente em cartas dos escreventes Ruzinete Rocha (que nasceu em 1931), Lourival Rocha (que nas nasceu em 1922) e Walter Oliveira (que nasceu em 1960) há formas associadas ao pronome $t u$, que, como mostra a autora, estão sempre em cartas com conteúdos amorosos. Queremos destacar aqui que, justificados os poucos (em sócio-discursivos bem específicos) usos de formas do $t u$ para a referência ao complemento verbal de segunda pessoa do singular na amostra, há um uso expressivo e quase categórico de formas do você em cartas de quase todos os escreventes, o que parece revelar um sistema de você já implementado na escrita no Rio Grande do Norte no nordeste brasileiro, desde a primeira metade do século XX, nas funções acusativa, dativa e oblíqua.

Quando analisadas as amostras em separado por função, Moura (2017) mostra que as formas de você na função de complemento dativo são mais produtivas entre os escreventes ilustres, como mostram os dados da tabela 2 a seguir: 


\begin{tabular}{cccc}
\hline & VOCE & TU & TOTAL \\
\hline ILUSTRES & $\mathbf{8 8 , 3 \% - 1 2 8 / 1 4 5}$ & $11,7 \%-17 / 145$ & $47,5 \%-145 / 305$ \\
NÃO ILUSTRES & $65 \%-104 / 160$ & $35 \%-56 / 160$ & $52,5 \%-160 / 305$ \\
\hline
\end{tabular}

Tabela 2: Distribuição de complementos verbais com referência à segunda pessoa do singular na função dativa em relação à categoria social (MOURA, 2017, p. 120).

Do total de 145 dados de informantes ilustres, 128 (88,3\%) são com formas associadas ao inovador você em oposição ao tu com 17 dados (11,7\%). O escrevente ilustre Luís da Câmara Cascudo, por exemplo, empregava nas cartas que escrevera a Mário de Andrade apenas formas dativas associadas ao inovador você ou formas nulas, como exemplificam os excertos a seguir.

(13) [... Sempre LHE direi que recebi sua carta [...]. (Carta de Câmara Cascudo a Mário de Andrade, 26|6|25).

(14) [...] Direi A V. que "Raça" é tronco de raminho fino. Laranja muito doce fica secca. [...]. (Carta de Câmara Cascudo a Mário de Andrade, 26|6|25).

(15) [...] O argentino-columbiano leu o Escrava vezes e está suando de enthusiasmo. Mandei seu endereço para que elle enviasse a chronica a respeito do livro. Para meu fôro intimo pergunto A V.[...] (Carta de Câmara Cascudo a Mário de Andrade, $9|7| 25)$.

Em relação ao não preenchimento do complemento com referência à segunda pessoa do singular, Moura (2017) encontrou apenas 55 ocorrências ao longo do século XX, sendo $42(76,4 \%)$ dessas em função dativa, conforme dado em (17), 12 (21,8\%) em acusativa (18) e 1 (1,8\%) em oblíqua (19):

(16) $[\ldots]$ Remetto $\varnothing$ esse livréco meu. O primeiro. Não leia. Registre e mande um abraço pela minha grande prova de amizade. (Carta de Câmara Cascudo para Mário de Andrade, 25|8|24).

(17) [...] O primeiro. Não Ø leia. Registre e mande um abraço pela minha grande prova de amizade. (Carta de Câmara Cascudo para Mário de Andrade, $25|8| 24)$.

(18) [...] O melhor que tenho tido em minha vida é não esperar senão bonde e 
missa. Idéas, elogios, rapapés, frechisbeques litterários, vem quando contra o provável. Tradução - a única maneira d'eu desconfiar $\emptyset$ e de seu talento seria um livro compreendido inteiramente. [...]. (Carta de Câmara Cascudo para Mário de Andrade, 25|8|24).

Para os complementos verbais dativos com referência à segunda pessoa, as formas nulas são mais frequentes em cartas de escreventes com o subsistema exclusivo de você e, mais especificamente, na escrita do informante ilustre Luiz da Câmara Cascudo, como ilustra o gráfico na figura 4.

\section{$\multimap-$ COMPLEMENTOS DATIVOS NÃO REALIZADOS NAS CARTAS DO RN}

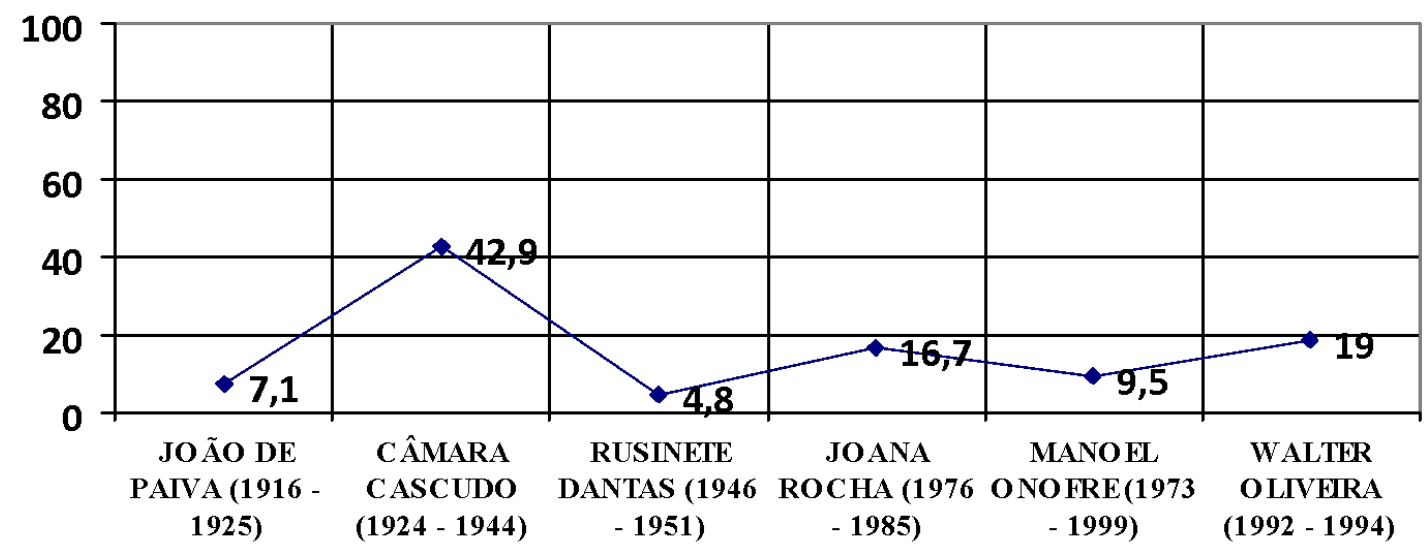

Figura 4: Distribuição dos complementos dativos não realizados quanto à diferenciação dos escreventes (MOURA, 2017, p. 129).

Esses resultados deixam claro que formas pronominais de complementos verbais de segunda pessoa associadas ao pronome você são quase categóricas em cartas pessoais no estado do Rio Grande do Norte no curso de todo o século XX, e as poucas formas de tu são motivadas por relações interpessoais entre os escreventes em cartas pessoais de amor. Das formas associadas ao pronome você, o pronome the é muito recorrente e os nulos são pouco frequentes no século XX, estando associados em sua grande maioria a complementos dativos. O uso do pronome the como complemento de segunda pessoa era já muito recorrente em cartas do Rio Grande do Norte do início do século XX mesmo em cartas que tratam de assuntos mais íntimos, ambiente favorecedor do uso das formas associadas ao $t u$.

Das formas acusativas analisadas por Moura (2017), foram encontradas 220 ocor- 
rências, distribuídas em 143 (65\%) associadas ao pronome tu e 77 (35\%) ao pronome você. As formas encontradas foram os pronomes $o / a(s)$, você, te e the e dessas, esse último na função acusativa é a forma mais recorrente, mostrando um quadro diferente daquele encontrado em cartas da região Nordeste, como também mostram Andrade, Carneiro e Lacerda (2016) para cartas da Bahia.

Considerando esse quadro, para melhor visualizar as inovações no uso dos complementos verbais em cartas pessoais do Nordeste brasileiro, numa perspectiva diatópico-diacrônica, apresentamos na próxima seção uma análise particularizada das formas dativas com referência à segunda pessoa do singular.

\section{Complementos dativos}

\subsection{Região Nordeste}

Costa da Silva (2017) investigou um corpus de 248 cartas pessoais escritas entre 1910 a 1999 dos estados do Rio Grande do Norte ${ }^{11}$, de Pernambuco e da Bahia no Nordeste brasileiro e apresenta uma análise variacionista de 610 ocorrências de complementos dativos com referência à segunda pessoa do singular, considerando as seguintes variantes: (a) os pronomes átonos te e vos e ti preposicionado (cf. 19), (b) o clítico the (20), (c) o pronome nulo (21), e (d) os pronomes você e tu preposicionados (22).

(19) a. [20,2 CP RN] ainda não tenho uma resposta pra TE dizer. (Walter a Lucinha, São Paulo 18.10.91).

b. Com os mais attenciosos cumprimentos VOS apresento o XI volume dos "Archivos do Museu (Alipio de Miranda Ribeiro ao Excelentissimo Sr. Governador do Estado da Bahia, Feira de Santana, 17-12-1901).

b. Este que é capaz de dar a vida POR TI caso fosse preciso. (Walter a Lucinha, São Paulo, 08-12-1992).

(20) [20,2 CP RN] também não creio estar pedindo-LHE nada demais. (Walter a Lucinha, São Paulo, 22-05-93).

(21) [20,2 CP RN] Lucinha, peço (Q) que se possível mim ligue domingo. (Walter a Lucinha, São Paulo, 20-11-92).

(22) a. [20,2 CP RN] Você creia ou não, nunca escrevi PARA VOCÊ o que não sentisse. (Renné a Otto, Ilhéus, 14-04-49).

b. [20,2 CP RN] o passado nêgro não quero ja mais, apelo PARA TU, para o futuro para que o meu sonho sêja realizado. (Lourival a Ruzinete, Mumbaça, 17-02-1946).

\footnotetext{
${ }^{11}$ No corpus investigado por Costa da Silva está parte das cartas analisadas por Moura (2017).
} 
A implementação das quatro variantes para a expressão do complemento dativo com referência à segunda pessoa do singular nas cartas dos três estados no curso do século XX em três períodos pode ser observada nos gráficos da figura 5 a seguir ${ }^{12}$ :

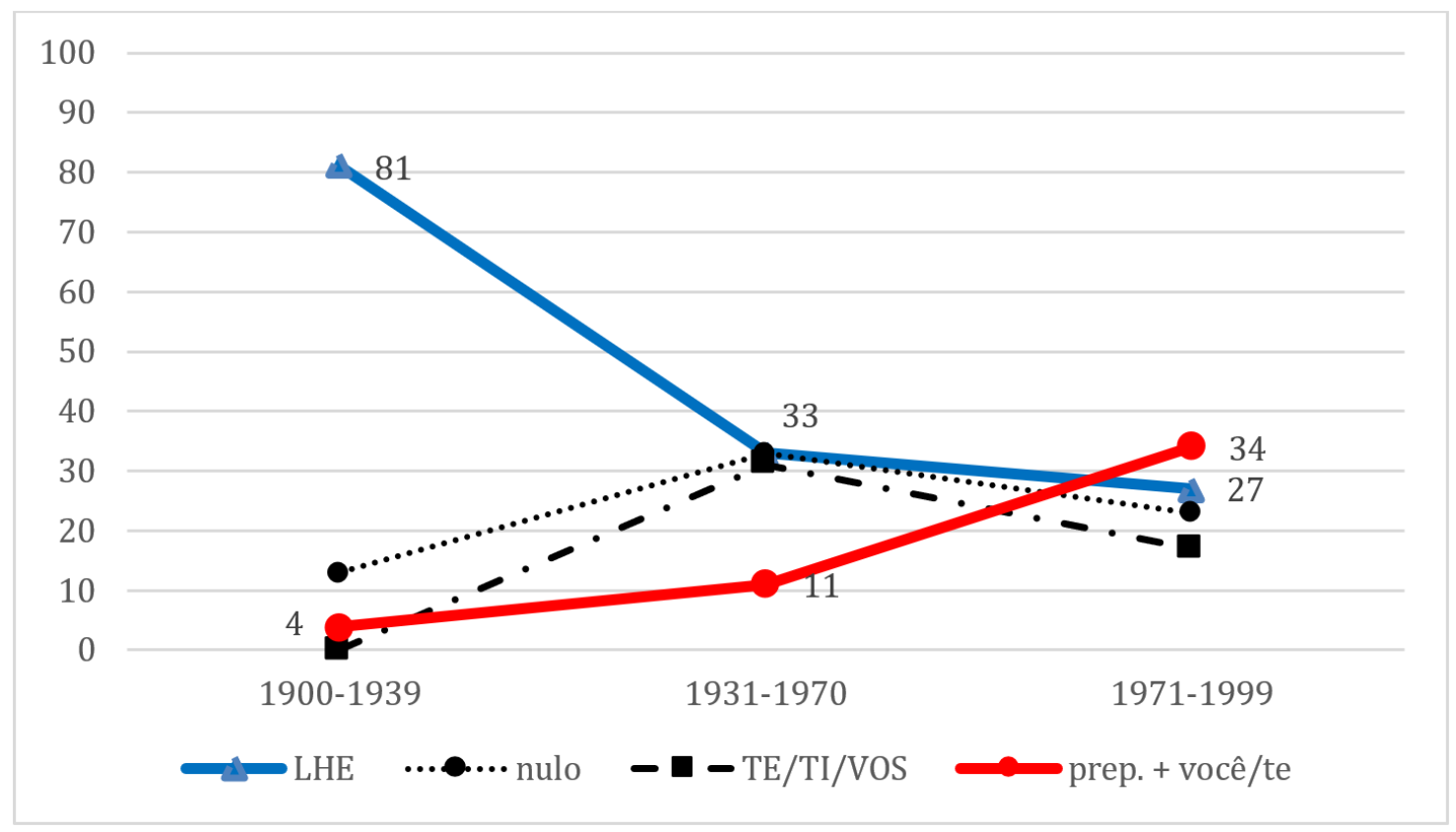

Figura 5: Implementação das formas dativas de segunda pessoa do singular em cartas pessoais da região Nordeste (1900-1999) - (COSTA DA SILVA, 2017, p. 76).

O seguinte quadro pode ser sistematizado do seguinte modo:

As formas pronominais te/ti/vos já não são recorrentes em textos de 1900 a 1930. Há um aumento na frequência de uso dessas formas ao longo das décadas seguintes, mas, como aponta o autor, esse aumento ocorre nas cartas de 1931 a 1970, da escrevente Ruzinete que faz uso categórico de um sistema de $t u$ (conforme quadro 1 acima) e escreve todas as correspondências aqui analisadas para o seu namorado/noivo/marido no período de 1946 a 1972. De acordo com a análise de Costa da Silva, essa não é a tendência geral nas cartas analisadas, mas uma particularidade das cartas da escrevente Ruzinete.

Há uma queda bastante acentuada na frequência de uso do pronome the de 19001930 (81\%) para os períodos de 1931-1970 (33\%) e de 1971-1999 (27\%). O uso da forma inovadora the já parece se mostrar muito frequente em textos do início do século XX e cai significativamente a partir de textos de 1970.

${ }^{12}$ Destacamos aqui que o interesse central nesta seção não é analisar a variação entre as formas do paradigma de você e de $t u$, motivo pelo qual agrupamos todas as formas preposicionadas, mesmo entendendo que se tratam de paradigmas distintos. 
Há um aumento na frequência de nulos para a expressão do complemento dativo com referência à segunda pessoa do singular: de 13\% em textos de 1900-1930, sobe para 31\% em textos de 1931-1970 e passa a 23\% em textos de 1970-1999.

Há um evidente incremento nas cartas da variante inovadora com formas preposicionadas (preposição + você/tu) no curso do século XX, de 4\% para 11\% e 34\% em textos escritos a partir de 1931.

Podemos conjeturar que a mudança associada ao uso da forma inovadora the para a expressão do complemento dativo com referência à segunda pessoa do singular já estava por completo implementada no sistema de dativos no início do século XX na escrita do Nordeste e perde espaço primeiro para os nulos, que começam a aparecer timidamente em cartas do início do século XX, e depois para as formas mais inovadoras preposicionadas, cuja frequência de uso aumenta de 4\% de 1900-1930 para 11\% e 34\% em cartas das décadas de 1931-1970 e 1971-1999.

\subsection{Região Sudeste}

Oliveira (2015) analisou 318 cartas escritas entre o período de 1880 a 1980 do Rio de Janeiro e encontrou 811 ocorrências de complementos dativos, estando os dados distribuídos em quatro sincronias nos gráficos da figura 6 a seguir. ${ }^{13}$

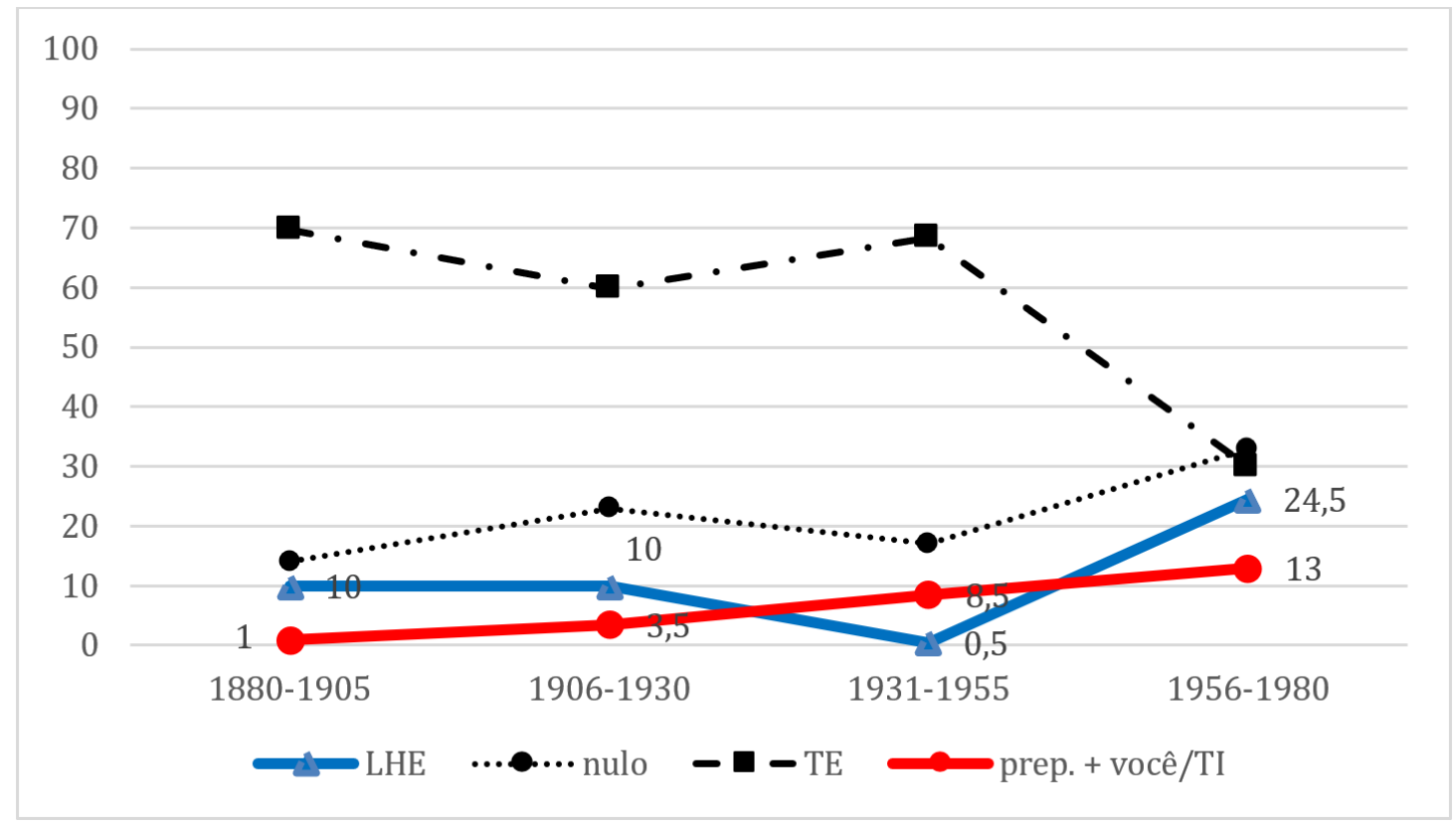

Figura 6. Implementação das formas dativas de segunda pessoa do singular em cartas pessoais do Rio de Janeiro (1900-1999) - (OLIVEIRA, 2015, p. 87).

\footnotetext{
${ }_{13}$ Apresentamos nos gráficos apenas os resultados referentes às variantes the, te, preposição (a/para) + você e nulo do estudo e Oliveira (2015), a fim de compararmos com os resultados de Costa da Silva (2017) para a região Nordeste.
} 
Em linhas gerais, as tendências das mudanças atestadas em cartas da região Nordeste para as quatro variantes parecem ser as mesmas que as encontradas em cartas cariocas. Há, no entanto, algumas especificidades em relação ao período em que observamos a implementação das variantes:

(i) Sobre a forma pronominal te, há uma queda na frequência de uso de 69,6\% em cartas de 1880-1905 para 30\% nas de 1956-1980.

(ii) Sobre a forma pronominal the, há nas cartas cariocas um tímido incremento na frequência de uso das cartas de 1880-1905 (10\%) para as de 1956-1989 $(24,5 \%)$. A frequência de uso da forma the se contrasta àquela encontrada em cartas do Nordeste, pois no RJ o lhe parece se implementar no curso do século XX, com um significativo aumento em cartas da década de 1931.

(iii) Sobre as formas nulas, Oliveira mostra um leve incremento na frequência de uso de 14,5\% em 1880-1905 para 30\% em 1956-1989 e esse aumento também parece ser sensível à escrita a partir da década de 1931.

(iv) Sobre as formas preposicionadas, considerando que Oliveira (2015) não encontra nenhuma ocorrência de prep. $+t u$, há um pequeno incremento na frequência de uso da forma prep. + você inovadora da gramática do PB, de 1,4\% nas décadas de 1880 a 1905 para 13\% na segunda metade do século XX, em cartas de 1956 a 1980.

Fica evidente que a tendência na frequência de uso dos nulos acompanha a tendência de uso do pronome the nas cartas cariocas e esse quadro é diferente daquele encontrado nas cartas do Nordeste, em que as formas preposicionadas (preposição + você/tu) desenham uma curva de mudança que se implementa no sistema do século XX.

\subsection{Região Sul}

Esse quadro se apresenta ainda mais diferente em cartas da região Sul. Nunes de Souza (2015) analisa três conjuntos de cartas de escreventes de duas cidades do estado de Santa Catarina de 1882 a $1992^{14}$. Dos resultados apresentados pela autora, fica evidente que em cartas do estado de SC, no que se refere às quatro variantes:

(i) O uso do pronome te é ainda muito frequente no final do século XIX e no século XX, de 1882 a 1992.

\footnotetext{
${ }^{14}$ A análise da autora toma como referência uma amostra de 1882 a 1898 com cartas de Cruz e Sousa; uma amostra de 1932 a 1992 com cartas de Maura de Senna; e uma amostra de 1984 a 1992 de Harry Laus.
} 
(ii) A frequência de uso do pronome lhe como complemento dativo com referência à segunda pessoa do singular é muito baixa em toda a amostra, com poucos dados em cartas de Maura de Senna, uma escrevente que mostra sempre um aspecto mais inovador, segundo a autora.

(iii) Os nulos são de igual modo muito pouco frequentes.

(iv) Quase não há formas preposicionadas nas cartas catarinenses. A autora encontra apenas 5 ocorrências de prep +você nas mesmas cartas de Maura de Senna.

Os mesmos resultados para os estados do Rio de Janeiro e de Santa Catarina podem ser encontrados no estudo de Oliveira, Carvalho e Silva (a sair), com base em uma amostra extraída de 255 cartas particulares cariocas e catarinenses. Os autores analisaram 291 dados em cartas de SC, com as variantes assim distribuídas: $77 \%$ de te; $8,2 \%$ de $l$ he; $11,3 \%$ de nulos; $2,4 \%$ de prep. (a/para) ti; e $1 \%$ de (a/para você); e 357 dados em cartas do RJ, assim distribuídos: $55,2 \%$ de te; $10,4 \%$ de the; $25 \%$ de nulo; $2,2 \%$ de preposição (a/para) ti; e $6,4 \%$ de (a/para você). Esses resultados ratificam aqueles apresentados em Oliveira (2015) para o RJ e em Nunes de Souza (2015) para SC. A evolução para cada uma das variantes nos dados de SC na análise de Oliveira, Carvalho e Silva, em dois períodos, o final do século XIX e a segunda metade do século XX, estão expressos nos gráficos da figura 7 a seguir.

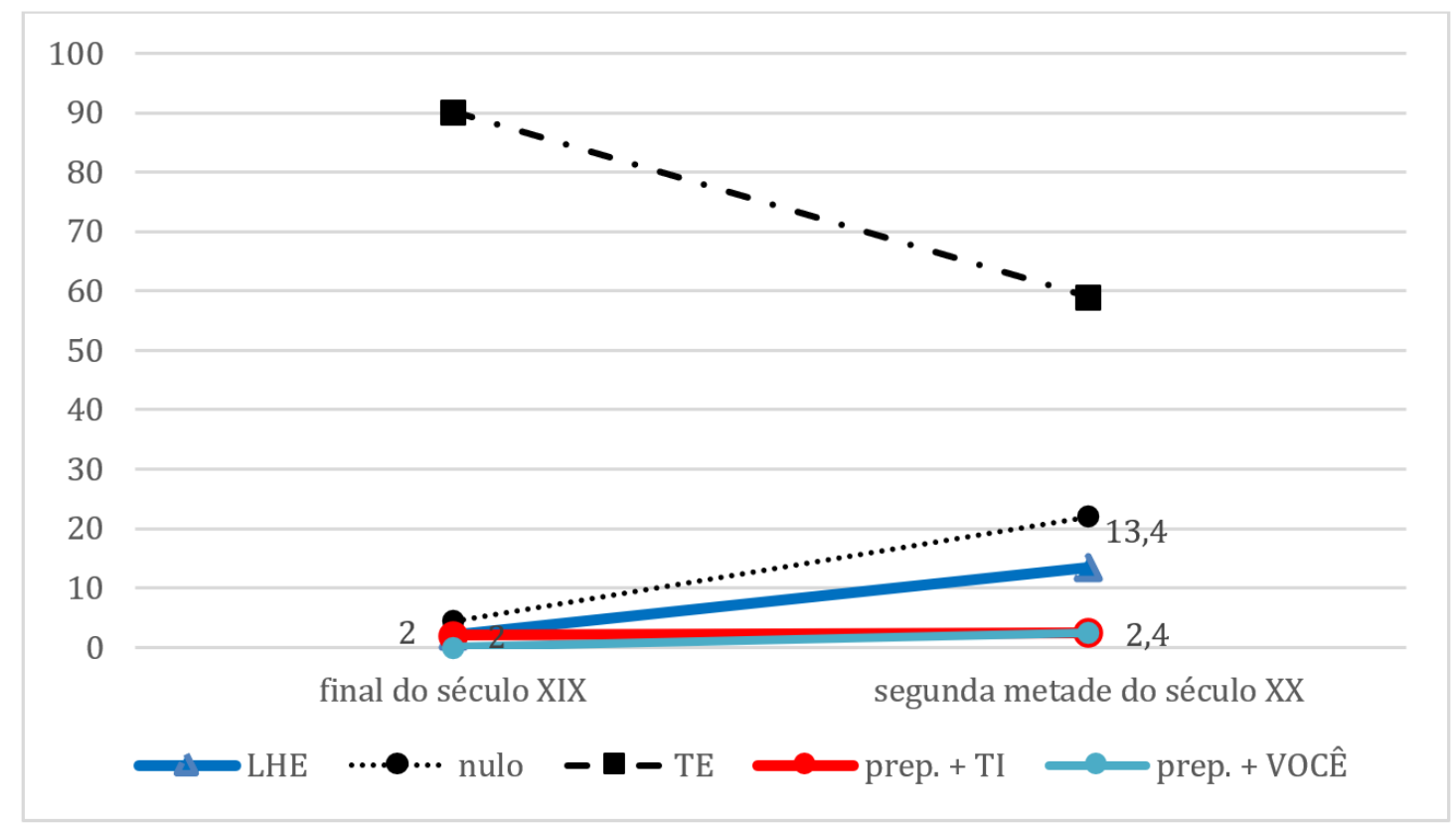

Figura 7: Implementação das formas dativas de segunda pessoa do singular em cartas pessoais de Santa Catarina (final do século XIX e segunda metade do século XX) (OLIVEIRA; CARVALHO; SILVA, a sair, p. 10) 
Esses resultados deixam ainda mais evidente a implementação das variantes para a expressão do complemento dativo com referência à segunda pessoa do singular em cartas do estado de SC, com o uso do pronome te ainda muito frequente no final do século XIX $(90,2 \%)$ e na segunda metade do século XX (56\%); um pequeno aumento na frequência de uso do pronome the, com 13,4\% em cartas da segunda metade do século XX; um pequeno incremento da forma nula; e a quase ausência de formas preposicionadas, com as preposições a ou para + ti ou você na amostra.

Os resultados que sistematizamos nesta seção sobre os complementos dativos com referência à segunda pessoa do singular em cartas de três regiões do Brasil no curso dos séculos XIX e XX mostram que a implementação no contínuo temporal das variantes é diferente. Em cartas da região Nordeste, há uma distribuição diacrônico-diatópica bastante particular em que (i) a variante pronominal te é significativamente menos frequente já no início do século XX; (ii) a variante inovadora the já se mostra implementada no sistema pronominal desse período e o que se observa é uma acentuada queda na frequência de uso dessa forma no curso do século XX; e (iii) a frequência de uso das formas (mais) inovadoras nulas e preposicionadas, sobretudo desta última, são incrementadas no sistema.

\section{Sumarizando para concluir: particularidades das formas pronominais completivas de verbo com referência à segunda pessoa na escrita do Nordeste brasileiro em comparação com demais regiões}

Os resultados que retomamos neste artigo nos permitem delinear (o início de) um mapeamento diatópico-diacrônico dos complementos verbais com referência à segunda pessoa em cartas pessoais escritas em três regiões do Brasil dos séculos XIX e XX e apresentar mais argumentos para a hipótese defendida em Martins et al. (2015) e Martins (a sair) de que formas inovadoras da gramática do $\mathrm{PB}$ se implementam primeiro na região Nordeste quando comparada com as regiões Sudeste e Sul.

Os resultados de Moura (2017) mostram que formas associadas ao inovador você são mais recorrentes para os complementos verbais nas funções acusativa, dativa e oblíqua em cartas do estado do Rio Grande do Norte no século XX. Das formas associadas ao pronome você, o pronome the é muito recorrente e os nulos são poucos frequentes em todo o curso do século XX, estando associados em sua grande maioria a complementos dativos. O uso do pronome the como complemento de segunda pessoa era já mais fre- 
quente, mesmo em cartas com temáticas mais íntimas, ambiente favorecedor do uso das formas associadas ao $t u$.

Com um olhar verticalizado para os complementos dativos com referência à segunda pessoa, os resultados de Costa da Silva (2017) mostram que a mudança associada ao uso da forma inovadora the parecia já estar por completo implementada no sistema de dativos no início do século XX na escrita do Nordeste e vai perdendo espaço primeiro para os nulos, que começam a aparecer timidamente em cartas do início do século XX, e depois para as formas mais inovadoras preposicionadas, cuja frequência de uso aumenta de 4\% de 1900-1930 para 11\% e 34\% em cartas das décadas de 1931-1970 e 1971-1999.

Assim, podemos concluir que em cartas da região Nordeste há uma distribuição diacrônico-diatópica bastante particular em que (i) a variante pronominal te é significativamente menos frequente já no início do século XX; (ii) a variante inovadora the já se mostra implementada e o que observamos na escrita é uma acentuada queda na frequência de uso dessa forma; e (iii) a frequência de nulos aumenta, assim como aumenta significativamente a frequência das formas preposicionadas (prep. + você e mesmo prep. $+t u)$. Esse quadro corrobora a hipótese de que a escrita no Nordeste apresenta traços inovadores da gramática do $\mathrm{PB}$ que se antecedem no contínuo temporal no curso dos séculos XIX e XX. Muito naturalmente, uma amostra com um número maior de dados extraídos de diferentes gêneros textuais deve ser analisada para que possamos colorir com mais propriedade um mapa dos pronomes complementos da escrita no vasto território do Brasil dos séculos XIX e XX.

\section{Referências}

ANDRADE, A. L.; CARNEIRO, Z. O. N.; LACERDA, M. F de O. Formas tratamentais em cartas baianas: sujeito e outras funções. Cadernos de Estudos Linguísticos, v. 58, p. 257, 2016.

BROWN, R.; GILMAN, A. The Pronouns of power solidarity. In: Sebeok, T.A. (ed.), Style in

Language. Cambridge, Mass: MIT Press, 1960, p. 253-276.

CONDE SILVESTRE, J. C. Sociolinguística histórica. Madrid: Gredos, 2007.

COSTA DA SILVA, F. O emprego das formas dativas de segunda pessoa na escrita do Nordeste brasileiro do século XX: uma mudança em curso. Dissertação (Mestrado em Estudos da Linguagem) - Universidade Federal do Rio Grande do Norte, 2017.

LOPES, C. R.; MARCOTULIO, L., L.; BRITO, M. C. R. DE ; OLIVEIRA, T. L.; SOUZA, J. P. F ; COELHO, I. L.; GOMES, V. S.; CARNEIRO, Z.; ANDRADE, A. L.; MARTINS, 
M. A.; OLIVEIRA, M. F.; MONTE, V. M.; SOUZA, C. M. N.; BALSALOBRE, S. R. G.; MOURA, K. K.; CRUZ, I. A.; CARDOSO, N. D. A reorganização no sistema pronominal de 2a. pessoa na história do português brasileiro: posição de sujeito. In: LOPES, C. (Org.). História do português brasileiro: mudança sintática das classes de palavra - perspectiva funcionalista. 1.ed.São Paulo: Editora Contexto, 2018, v. 4, p. 7-105.

LOPES, C. R. dos S.; RUMEU, M. C. de B. A difusão do você pelas estruturas sociais carioca e mineira dos séculos XIX e XX. LaborHistórico, Rio de Janeiro. v. 1, p. 12-25, 2015.

LOPES, C.; CAVALCANTE, S. R. de O. A cronologia do voceamento no português brasileiro: expansão de você sujeito e retenção do clítico te. Linguística, Madrid, vol. 25, 2011.

MARTINS, M. A.; ANDRADE, A. L. de; MOURA, K. K.; LACERDA, M.; GOMES, V. S.; CARNEIRO, Z. Para um panorama socio-histórico das formas de tratamento na função de sujeito na região nordeste. LaborHistórico, Rio de Janeiro. v. 1, p. 26-48, 2015.

MARTINS, M. A. Singularidades na sintaxe do português brasileiro escrito na região nordeste nos séculos XIX e XX. A sair.

MOURA, K. K. Formas de P2 na posição de complemento verbal em cartas pessoais norterio-grandenses do século XX. 2017. Tese (Doutorado em Linguística Teórica e Descritiva) - Centro de Ciências Humanas, Letras e Artes. Departamento de Letras, Universidade Federal do Rio Grande do Norte, Natal, 2017.

MOURA, K. K. A implementação do você em cartas pessoais Norte-rio-grandenses do século XX. 2013. Dissertação (Mestrado em Linguística Teórica e Descritiva) - Centro de Ciências Humanas, Letras e Artes. Departamento de Letras, Universidade Federal do Rio Grande do Norte, Natal, 2013.

NUNES DE SOUZA, C. COELHO, I. L. Caminhos para a investigação da alternância de pronomes de segunda pessoa em Santa Catarina. LaborHistórico, Rio de Janeiro. v. 1, p. 49-61, 2015.

NUNES DE SOUZA, C.; COELHO, I. L. O sistema de tratamento em Santa Catarina: uma análise de cartas pessoais dos séculos XIX e XX. Revista do GELNE (UFC), v. 15, p. 213-243, 2013.

NUNES DE SOUZA, C. M. N. A alternância entre Tu e Você na correspondência de florianopolitanos ilustres no decorrer de um século. 2015. 181f. Tese (doutorado em Linguística) - UFSC, Santa Catarina, 2015.

OLIVEIRA, T. L; CARVALHO, B. B. A; SILVA, T. F. T. A. Convergências e divergências na expressão do dativo de segunda pessoa: análise de cartas pessoais catarinenses e cariocas dos séculos XIX e XX. In: COELHO, I. L.; MONGUILHOTT, I. O. S; MARTINS, M. A.; GÖRSKI, E. M. Aspectos sócio-históricos e linguísticos do português de Santa Catarina dos séculos XIX e XX. Editora da UFSC, Florianópolis, a sair. 
OLIVEIRA, T. L. de. Os pronomes dativos de $2^{\text {a }}$ pessoa na escrita epistolar carioca. LaborHistórico, Rio de Janeiro. v. 1, p. 81-98, 2015.

WEINREICH, U.; LABOV, W.; HERZOG, M. Fundamentos empíricos para uma teoria da mudança linguística. Trad. Marcos Bagno. São Paulo: Parábola, 2006. 